\title{
Colorectal Liver Metastases: A Never Ending Story
}

\author{
Min Ro Lee, Jong Hun Kim \\ Research Institute of Clinical Medicine, Chonbuk National University Medical School, Jeonju, Korea
}

\section{See Article on Page 92-100}

To improve the quality of life and outcomes for patients with colorectal liver metastases, we would like to emphasize some points.

First, a colorectal multidisciplinary teams (MDT) should also include a specialized hepatobiliary MDT that has the expertise and the facilities to provide surgery for patients with liver metastases. The cases of patients being considered for treatment of hepatic metastases should be discussed at a multidisciplinary meeting in which the participants have experience in the management of liver metastases [1].

Second, traditional risk factors, as well as the indications and the contraindications, for a hepatic resection should be abandoned. The present principle as to resectability is that resection should be performed if all metastases, regardless of their sizes, number, locations and distribution, can be removed while leaving a sufficient remaining liver parenchyma [2]. As is known, the number of liver metastases, the spread of colorectal cancer to the lymph nodes, the maximum size of the metastases, the preoperative carcinoembryonic antigen level, the extrahepatic spread, and the use of a nonradical resection represent independent risk factors for recurrence $[3,4]$. Third, All resources should be used. Perioperative chemotherapy, portal vein embolization, a 2-stage hepatectomy, and local ablative therapies might improve outcomes.

\section{CONFLICT OF INTEREST}

No potential conflict of interest relevant to this article was reported.

\section{REFERENCES}

1. Garden OJ, Rees M, Poston GJ, Mirza D, Saunders M, Ledermann J, et al. Guidelines for resection of colorectal cancer liver metastases. Gut 2006;55 Suppl 3:iiil-8.

2. Misiakos EP, Karidis NP, Kouraklis G. Current treatment for colorectal liver metastases. World J Gastroenterol 2011;17:406775 .

3. Spelt L, Andersson B, Nilsson J, Andersson R. Prognostic models for outcome following liver resection for colorectal cancer metastases: a systematic review. Eur J Surg Oncol 2012;38:16-24.

4. Jang KU, Kim CW, Kim KH, Lim SB, Yu CS, Kim TW, et al. Prognostic factors in terms of the number of metastatic nodules in patients with colorectal cancer liver metastases. Ann Coloproctol 2016;32:92-100. 